\title{
Analysis of therapeutic potential of preclinical models based on DR3/TL1A pathway modulation (Review)
}

\author{
YUNHONG YU* ${ }^{*}$ PENG JIANG* ${ }^{*}$, PAN SUN, NA SU and FANGZHAO LIN \\ Institute of Blood Transfusion, Chinese Academy of Medical Science and Peking \\ Union Medical College, Chengdu, Sichuan 610052, P.R. China
}

Received June 23, 2020; Accepted September 11, 2020

DOI: $10.3892 /$ etm.2021.10125

\begin{abstract}
Death receptor 3 (DR3) and its corresponding ligand, tumor necrosis factor-like ligand 1A (TL1A), belong to the tumor necrosis factor superfamily. Signaling via this receptor-ligand pair results in pro-inflammatory and anti-inflammatory effects. Effector lymphocytes can be activated to exert pro-inflammatory activity by triggering the DR3/TL1A pathway. By contrast, DR3/TL1A signaling also induces expansion of the suppressive function of regulatory $\mathrm{T}$ cells, which serve an important role in exerting anti-inflammatory functions and maintaining immune homeostasis. Preclinical evidence indicates that neutralizing and agonistic antibodies, as well as ligand-based approaches targeting the DR3/TL1A pathway, may be used to treat diseases, including inflammatory and immune-mediated diseases. Accumulating evidence has suggested that modulating the DR3/TL1A pathway is a promising therapeutic approach for patients with these diseases. This review discusses preclinical models to gauge the progress of therapeutic strategies for diseases involving the DR3/TL1A pathway to aid in drug development.
\end{abstract}

\section{Contents}

1. Introduction

2. Expression and composition of TL1A and DR3

3. DR3/TL1A signal transduction

4. Co-stimulation of effector immune cells

5. Co-stimulation of $\mathrm{CD} 4^{+} \mathrm{CD} 25^{+} \mathrm{Foxp}^{+}$Tregs

6. Conclusions and perspectives

Correspondence to: Professor Fangzhao Lin, Institute of Blood Transfusion, Chinese Academy of Medical Science and Peking Union Medical College, 26 Huacai Road, Chengdu, Sichuan 610052, P.R. China

E-mail: fangzhao.lin@ibt.pumc.edu.cn

${ }^{*}$ Contributed equally

Key words: DR3, TL1A, effector lymphocytes, regulatory T cells, preclinical models, therapeutic approach

\section{Introduction}

The tumor necrosis factor superfamily (TNFSF) consists of 19 ligands and 29 receptors $(1,2)$. Death receptor 3 (DR3) and tumor necrosis factor-like ligand 1A (TL1A) are a TNFSF receptor-ligand pair that serve an essential role in regulating immunity, inflammation, cell proliferation and death, angiogenesis, and tumor metastasis $(2,3)$. The expression of DR3 and TL1A has been demonstrated in mice and humans, and preclinical and clinical studies have shown that the DR3/TL1A pathway serves a dual role in the development of inflammatory and immune-mediated diseases (4). On one hand, interaction between DR3 and TL1A may trigger the proliferation of $\mathrm{T}$ effector cells and cytokine production by these cells, which accelerate disease progression (5-7). On the other hand, activation of the DR3/TLA pathway serves an anti-inflammatory role through the expansion of regulatory $\mathrm{T}$ cells (Tregs) and alleviates diseases (8-10).

Based on the role of the DR3/TL1A pathway in pro-inflammatory and anti-inflammatory processes, this review summarizes DR3-associated signals and reviews therapeutic strategies targeting the DR3/TL1A pathway in preclinical models, intending to facilitate the development of attractive drug candidates.

\section{Expression and composition of TL1A and DR3}

DR3. In the late 1990s, a clone was found to exhibit identity to the death domains (DDs) of cluster of differentiation 95 (CD95; 23\% identity) and tumor necrosis factor receptor-1 (TNFR-1; 47\% identity), which are both members of the TNFSF (11). Additionally, the homologies of the cysteine-rich repeats between the clone and CD95 and TNFR-1 were 22 and 26\%, respectively (11). Therefore, the clone was classified as a member of the TNFSF and was designated as DR3 (TNFRSF25, APO-3, TRAMP, WSL-1, TR3 or LARD) (11,12). DR3 is encoded by the Tnfrsf 25 gene located in the 4E1 region of the mouse chromosome (13) and 1p36.3 of the human chromosome (4). As a type I transmembrane protein with a calculated molecular weight of $45 \mathrm{kDa}$ and 417-amino acid (aa) sequence, full-length DR3 is composed of an $\mathrm{N}$-terminal signal sequence (aa 1-24), a repeat sequence consisting of four cysteine residues, two potential $\mathrm{N}$-linked glycosylation sites (aa 25-198), a transmembrane domain 
(aa 199-244), and an intracellular domain with a DD (aa 255-417) (14,15). Notably, DR3 is exclusively expressed in lymphocyte-rich tissues, including the thymus, spleen, colon and intestine (11); however, low levels of expression are detected in the fetal lung (16), kidney (17), hippocampus (18) and peritoneal tissue (12). At the cellular level, DR3 is mainly expressed in immune cells, including naïve or resting $\mathrm{CD}^{+}$ $\mathrm{T}$ cells, $\mathrm{CD}^{+} \mathrm{T}$ cells, natural killer $\mathrm{T}$ cells, innate lymphoid cells (ILCs), B cells and mononuclear cells $(10,19)$. Notably, sustained expression of DR3 is found in Tregs. However, DR3 also exists in non-immune cells, including bone cells (20) and endothelial cell colony-forming cells (21). Expression of DR3 is highly regulated in multiple pathologies. The levels of DR3 are significantly increased in inflammatory bowel disease (IBD) (22), pulmonary sarcoidosis (23) and psoriasis vulgaris (24). By contrast, DR3 expression in mononuclear cells is downregulated in diseases, including sickle cell anemia (25) and colon cancer (26).

TL1A. TL1A, also known as vascular endothelial growth inhibitor (VEGI)-251 or TNFSF15, is the only proven ligand for DR3 to date (5). TL1A is a single-pass type II transmembrane protein encoded by the Tnfsf 15 gene on chromosome 4 in mice and $9 q 32$ in humans (4). Similar to other TNFSF cytokines, membrane-bound TL1A can be cleaved by alternative splicing or through TNF- $\alpha$-converting enzyme, and is shed from the extracellular domain to form soluble TL1A (sTL1A) $(4,5,27)$. Notably, sTL1A may continue to efficiently activate DR3. Endothelial cells, dendritic cells (DCs), monocytes/macrophages, activated $\mathrm{T}$ cells and human umbilical vein endothelial cells have been identified as major sources of TL1A (5,28-30). Additionally, the expression of TL1A on DCs and macrophages is increased upon activation via the receptor for the Fc region of $\operatorname{IgG}(\mathrm{Fc} \gamma \mathrm{R})$ and Toll-like receptors (TLRs), including TLR2 and TLR4, while expression of TL1A on endothelial cells may be enhanced by interleukin-1 beta (IL-1 $\beta$ ) and TNF- $\alpha$ stimulation (15). Nevertheless, chondrocytes, synovial fibroblasts, tissue macrophages and lamina propria lymphocytes also express TL1A at low levels under conditions of inflammation or upon stimulation $(5,6)$. Therefore, the binding of TL1A to DR3 triggers signal transduction and exerts pro- and anti-inflammatory functions.

\section{DR3/TL1A signal transduction}

Upon binding to DR3 on immune cells, TL1A triggers an interaction between the DD of DR3 and the adaptor protein, TNFR-associated death domain (TRADD). Subsequently, TNFR-associated factor 2 and receptor-interacting protein 1 bind to the DR3-TRADD complex, leading to activation of mitogen-activated protein kinase (MAPK), nuclear factor $(\mathrm{NF})-\kappa \mathrm{B}$, and phosphoinositide 3-kinase (PI3K) signaling. Consequently, three distinct signaling cascades induce immune cell activation, proliferation and cytokine secretion (Fig. 1). The activation of DR3 on immune cells by TL1A is an important prerequisite for its pro-inflammatory and anti-inflammatory effects. Accumulating evidence has revealed that pharmacological blockade or agonistic activation of DR3/TL1A signaling is a novel and promising target for inflammatory or immune-mediated diseases $(6,8,10)$.

\section{Co-stimulation of effector immune cells}

Co-stimulatory molecules expressed by antigen-presenting cells and $\mathrm{T}$ cells appear to be indispensable for the activation of $\mathrm{T}$ cells. The absence of co-stimulatory signals leads to $\mathrm{T}$ cell incompetence (31). The TNFSF is considered as one such group of co-stimulatory molecules that activates T cells. Several studies have demonstrated that, as a lymphocyte co-stimulatory signaling pathway, DR3/TL1A amplifies effector $\mathrm{CD}^{+} \mathrm{T}$ cells in a non-specific manner to aggravate the pathology of inflammatory diseases by triggering the release of inflammatory cytokines. Furthermore, abundant evidence also indicates that DR3 on ILCs affects the progression of inflammatory diseases (32-34).

Co-stimulation of effector $C D 4^{+} T$ cells. A subset of $\mathrm{CD}^{+} \mathrm{T}$ cells activated by the DR3/TL1A signaling serves a pro-inflammatory role under established conditions. Decreased lung inflammation in $\mathrm{DR} 3^{-/}$mice is attributed to fewer $\mathrm{CD}^{+} \mathrm{T}$ cells in the alveolar passage following an ovalbumin (OVA) challenge (35). TL1A, alone or in combination with IL-12 and IL-18, has been found to boost the secretion of interferon- $\gamma(\mathrm{IFN}-\gamma)$ and TNF- $\alpha$, which are characteristic cytokines produced by Th1 cells $(19,36,37)$. Activation of the DR3/TL1A pathway may aggravate disease progression by boosting Th1 immune responses in SAMP1/YitFc (SAMP) mice with ileitis (28). Furthermore, Th2-induced immunopathology is exacerbated by the non-specific stimulation of lymphocytes by DR3 signaling. Th2-mediated immune responses result in high levels of IL-5 and IL-13 produced in the intestinal mucosa, as well as aggravated inflammation in SAMP mice with ileitis via DR3/TL1A signaling $(4,28,38)$. Additionally, Th2 cells, activated by the DR 3 axis and accompanied by high IL-13 production, have been implicated in allergic inflammation in mouse models $(39,40)$. Th17 cells show higher expression of DR3 compared with Th1 and Th2 cells (41). However, the role of DR3 signaling in Th17 differentiation is controversial. Inhibition of Th17 cell generation by DR3 signaling has been demonstrated in $\mathrm{CD}^{+} \mathrm{T}$ cells and spleen cells from humans and wild-type mice, respectively (42). By contrast, other studies have demonstrated that TL1A promoted Th17 cell differentiation and participates in the development of inflammation, such as rheumatoid arthritis (RA) (43) and experimental autoimmune encephalomyelitis (EAE) (44). Notably, the proliferation of Th17 cells was augmented upon DR3 activation. Pappu et al (44) verified that the decreased proliferation of Th17 cells in TL1A-deficient mice ameliorated the pathology of EAE. This evidence indicates that the DR3/TL1A axis aggravates inflammatory reactions triggered by activated Th17 cells. A recent study demonstrated that the DR3/TL1A pathway drives the differentiation of naïve $\mathrm{T}$ cells to Th9 cells, aggravating inflammatory pathology in an allergic lung inflammation model (7). Similarly, preclinical and clinical studies in chronic colitis have demonstrated that TL1A facilitates the differentiation of Th9 cells and increases IL-9 secretion, aggravating intestinal inflammation (45). Additionally, Tsuda et al (46) reported that TL1A induced the expression of basic leucine zipper ATF-like transcription factor 3 to promote Th9 cell differentiation and IL-9 production to drive intestinal inflammation. 


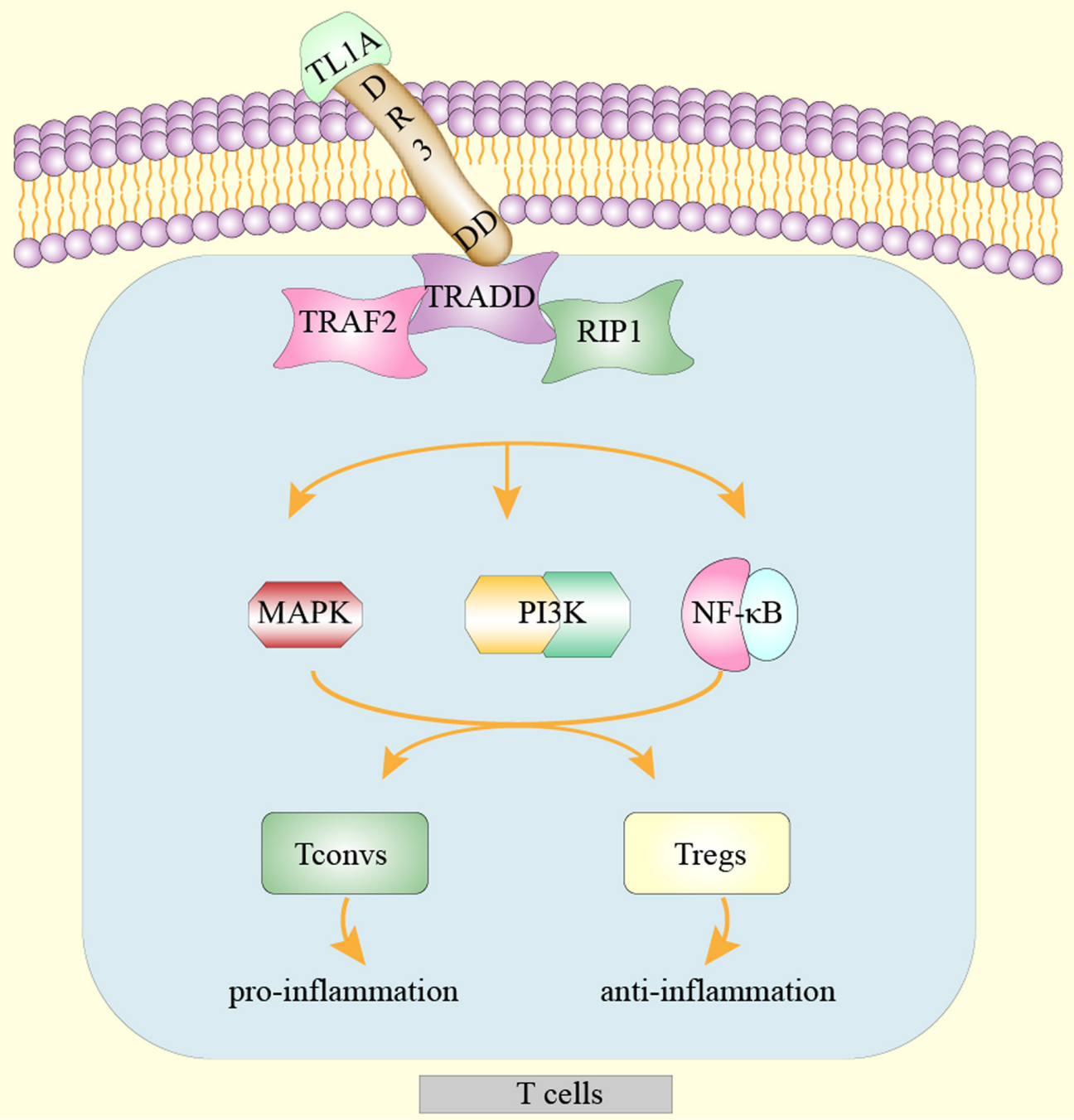

Figure 1. DR3/TL1A pathway in T cells. Upon binding to TL1A, the DD of DR3 signals via the TRADD, which in turn, recruits RIP1 and TRAF2 to form a signaling complex in T cells, accompanied by the downstream activation of MAPK, NF- $\kappa B$ and PI3K. The signaling ultimately triggers pro-inflammatory responses from Tconvs and anti-inflammatory signals from Tregs. DR3, death receptor 3; TL1A, tumor necrosis factor-like ligand 1A; DD, death domain; TRADD, TNFR-associated death domain; RIP1, receptor-interacting protein 1; TRAF2, TNFR-associated death domain; MAPK, mitogen-activated protein kinase; NF-kB, nuclear factor-кB; PI3K, phosphoinositide 3-kinase; Tconvs, conventional T cells; Tregs, regulatory T cells.

Co-stimulation of ILCs. In addition to T cells, the DR3/TL1A pathway co-stimulates ILCs. ILC2s and ILC3s are subsets of ILCs. DR3 signaling can expand ILC2s and ILC3s, driving IL-5 and IL-13 secretion from these cells. In vivo experimental evidence has demonstrated that ILC2s cause deterioration in allergic lung inflammation $(34,35,47)$. By contrast, ILC3s exert positive effects by increasing IL-22 production. Loss of DR3 signaling with decreased IL-22 production has been associated with a higher histopathological score in a DR3-deficient, dextran sulfate sodium (DSS)-induced colitis model $(33,48)$. Furthermore, an anti-DR3 antibody triggered the loss of ILC3s from the intestine, ultimately aggravating the colitis condition (32).

Therapeutic application. The DR3/TL1A pathway has been clearly implicated in several diseases, including allergic lung inflammation (35), psoriasis (5), IBD (4) and rheumatoid arthritis (43). The aforementioned diseases share a common molecular mechanism in which DR3 signaling exerts pleiotropic effects on the activation, differentiation, proliferation and cytokine release of ILC2s and T helper cells (including Th1, Th2, Th9 and Th17 cells). Therefore, these findings suggested that pharmacological blockade of the DR3/TL1A axis may have therapeutic value for human inflammatory and immune-mediated diseases. An anti-TL1A monoclonal antibody (anti-TL1A mAb) targeting the DR3/TL1A pathway has emerged as a promising anti-inflammatory therapeutic agent in preclinical studies $(5,6,31,49)$. Furthermore, unlike anti-TNF, anti-TL1A mAb may be relatively safe and effective because it does not induce immunodeficiency (50).

It is evident that TL1A/DR3 signaling dampens gut immune homeostasis and accelerates disease progression (4). Thus, blocking the TL1A/DR3 pathway may be a useful strategy for relieving IBD. Studies in animal models have demonstrated that anti-TL1A mAb exerts a protective function in DSS-induced chronic colitis by suppressing Th1 and Th17 cell activation (51). Additionally, in acute 2,4,6-trinitrobenzene-sulfonic acid (TNBS)-induced colitis involving increased production of Th1 cells and IFN- $\gamma$, blocking the DR3/TL1A axis with anti-TL1A mAb almost completely prevented weight loss and 
alleviated the histological score of inflammation (52). However, administration of anti-TL1A mAb, a neutralizing agent, mitigated the early phase, but not the late stage of TNF $\triangle \mathrm{ARE}{ }^{+}$ ileitis, thereby suggesting the existence of other DR3 ligands aside from TL1A (31). Of note, the aforementioned studies have only demonstrated a decreased in inflammation caused by anti-TL1A mAb rather than alleviation of intestinal fibrosis, a hallmark of IBD. In DSS, as well as in the adoptive T cell transfer chronic colitis models, treatment with anti-TL1A $\mathrm{mAb}$ resulted in a decrease in the number of myofibroblasts and fibroblasts, leading to a reversal of colonic fibrosis (53). Furthermore, Li et al (54) discovered that intestinal inflammation and fibrosis were attenuated in $\mathrm{T}$ cell transfer chronic colitis models. Clarke et al (6) also confirmed that anti-TL1A $\mathrm{mAb}$ significantly alleviated the clinical pathology of IBD by decreasing inflammatory cell filtration and colonic fibrosis. In general, therapeutic blockade of the DR3/TL1A pathway by anti-TL1A $\mathrm{mAb}$ has numerous advantages, including amelioration of intestinal inflammation and reversal of colonic fibrosis, compared with traditional treatment for IBD, which only controls intestinal inflammation.

In addition to IBD, blocking the DR3/TL1A pathway with anti-TL1A mAb relieves collagen-induced arthritis (49), strongly reduces inflammatory cell infiltration in OVA-induced asthma (6), and effectively alleviates the histopathological changes in a psoriasis-like mouse model (5). Taken together, these results suggested that anti-TL1A mAb has therapeutic potential for treating inflammatory and immune-mediated diseases (Table I).

\section{Co-stimulation of $\mathrm{CD}^{+} \mathrm{CD}^{+} 5^{+} \mathrm{Foxp3}^{+}$Tregs}

Basic characteristics of Tregs. Tregs are a subset of CD4 ${ }^{+} \mathrm{T}$ cells that function primarily to maintain the homeostasis of immune function by negatively regulating effector lymphocyte activation and proliferation (55). Tregs are mainly characterized by CD4, CD25 and Foxp3. Williams and Rudensky (56) reported that, rather than acquiring the ability to produce IL-2 and Th1 cytokines, the immunosuppressive function was eliminated in mature Tregs following the deletion of the FOXP3 gene. Therefore, Foxp3 is essential for maintaining the immunoregulatory function of Tregs. In addition to CD4 and Foxp3, Tregs express a high-affinity IL-2 receptor (IL-2R) that may bind IL-2R $\alpha$ (CD25), IL-2R $\beta$ (CD122) and IL-2Rס (CD132) (57). As expected, IL-2 is a critical signal for Treg differentiation.

Therapeutic application. Activation of DR3 using an anti-DR3 agonistic antibody or sTL1A has been shown to mediate Treg cell activation and expansion because of the constitutive expression of DR3 on Treg cells. DR3-mediated activation of Tregs mainly triggers the activation of MAPK, NF- $\kappa \mathrm{B}$ and PI3K signaling via DR3/TL1A signal transduction $(15,58,59)$, thereby exerting anti-inflammatory effects and preventing inflammatory and immune-mediated diseases in mice.

Due to the strong immunosuppressive function of Tregs, adoptive transfer of exogenously expanded Tregs or IL-2/IL-2 complexes expanded Tregs in vivo can alleviate a variety of immune-mediated diseases such as experimental autoimmune neuritis (60), headache disorders (61), systemic lupus erythematosus (62), IBD (63) and allograft tolerance (64-66), as well as inflammatory diseases such as transfusion-related acute lung injury $(67,68)$ in preclinical models. Moreover, adoptive Treg transfer and low-dose IL-2 therapy have been associated with disease improvement and unconspicuous adverse effects in patients (66). However, the ability to obtain an adequate number of Tregs through adoptive transfer limits their clinical use, while the cytotoxicity, off-target effects and short half-life of IL-2 therapy in vivo necessitate the use of approaches employing expanded Tregs (64).

Anti-DR3 agonist. Clone 4C12 is an anti-DR3 agonistic antibody that activates and expands Tregs and thus has been useful for preventing or treating diseases in preclinical models $(8,10,69)$. To begin with, the stimulation of DR3 using 4C12 leads to rapid and selective expansion of Tregs without influencing Tconvs $(8,9,70,71)$. Furthermore, 4C12 retains its capacity to expand Tregs ex vivo (8). Additionally, the half-life of 4C12 is 5 days (9), ensuring prolonged contraction of expanded Tregs following 4C12 treatment compared with treatment with IL-2 or IL-2 complexes (8). Prolonged contraction of expanded Tregs is important for ameliorating inflammatory and immune-mediated diseases.

Preclinical models have demonstrated that Tregs expanded by 4C12 may alleviate disease. Schreiber et al (8) first discovered that lung inflammation was alleviated following treatment with $4 \mathrm{C} 12$ compared with the control group in OVA-induced acute allergic pneumonia. Madierddi et al (69) also demonstrated that the administration of $4 \mathrm{C} 12$ relieved allergic pneumonia and suppressed EAE through the expansion of Tregs. At present, 4C12 is widely applied in the field of transplants, including organ transplant, tissue transplant and cell transplant, aiming to alleviate graft-versus-host disease (GVHD). For example, Tregs expanded in vivo by 4C12 may provide tolerance to cardiac allografts (71). Recipients transplanted with donor-expanded Treg by 4C12 exhibited enhanced skin allograft survival (72). Furthermore, the infusion of $4 \mathrm{C} 12$ in recipient mice enhances skin graft survival associated with boosted graft-infiltrating Tregs (73). Administration of 4C12 also efficiently ameliorated GVHD in hematopoietic stem cell transplantation (HSCT) mismatch mouse models. Several studies have suggested that donor-derived Tregs are more effective than recipient-derived Tregs for GVHD treatment $(74,75)$. Transfer of donor-derived Tregs expanded by 4C12 markedly protected mice from GVHD $(10,72,76)$. Notably, Nishikii et al (29) demonstrated that treatment of recipients with 4C12-induced Treg activation and proliferation was sufficient to dampen GVHD lethality prior to exposure to HSCT. By contrast, mice transplanted with Tregs that were expanded by 4C12 following HSCT exposure led to donor $\mathrm{T}$ cell proliferation and ultimately fueled GVHD (29). These findings demonstrated that activation of DR3 mitigated the lethality of GVHD, depending on the timing of triggering DR3. Due to the significance of IL-2 signals in DR3-mediated Tregs expansion (8), low-dose IL-2 combined with 4C12 for donors resulted in decreased GVHD morbidity and prolonged survival (10). Additionally, the absolute number of Tregs induced by that combination was larger than that observed following the treatment with 4C12 alone (10). Therefore, this therapeutic strategy may be an improvement for delaying allogeneic rejection. 


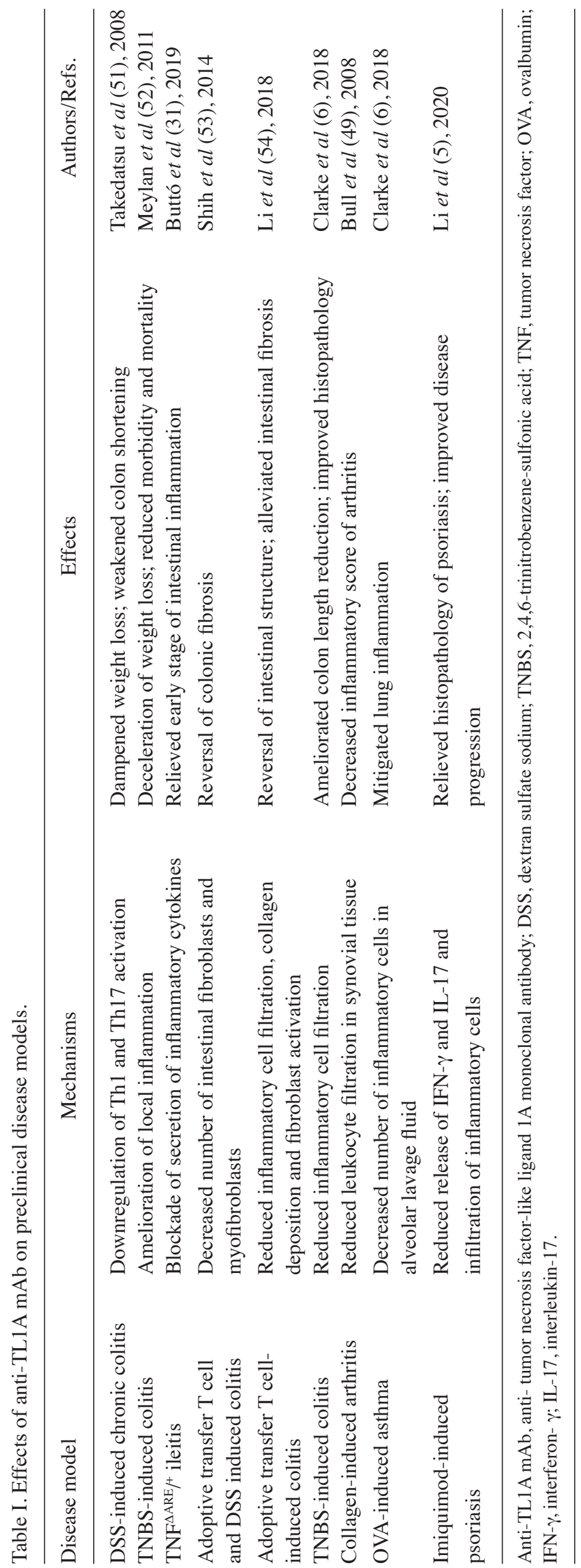




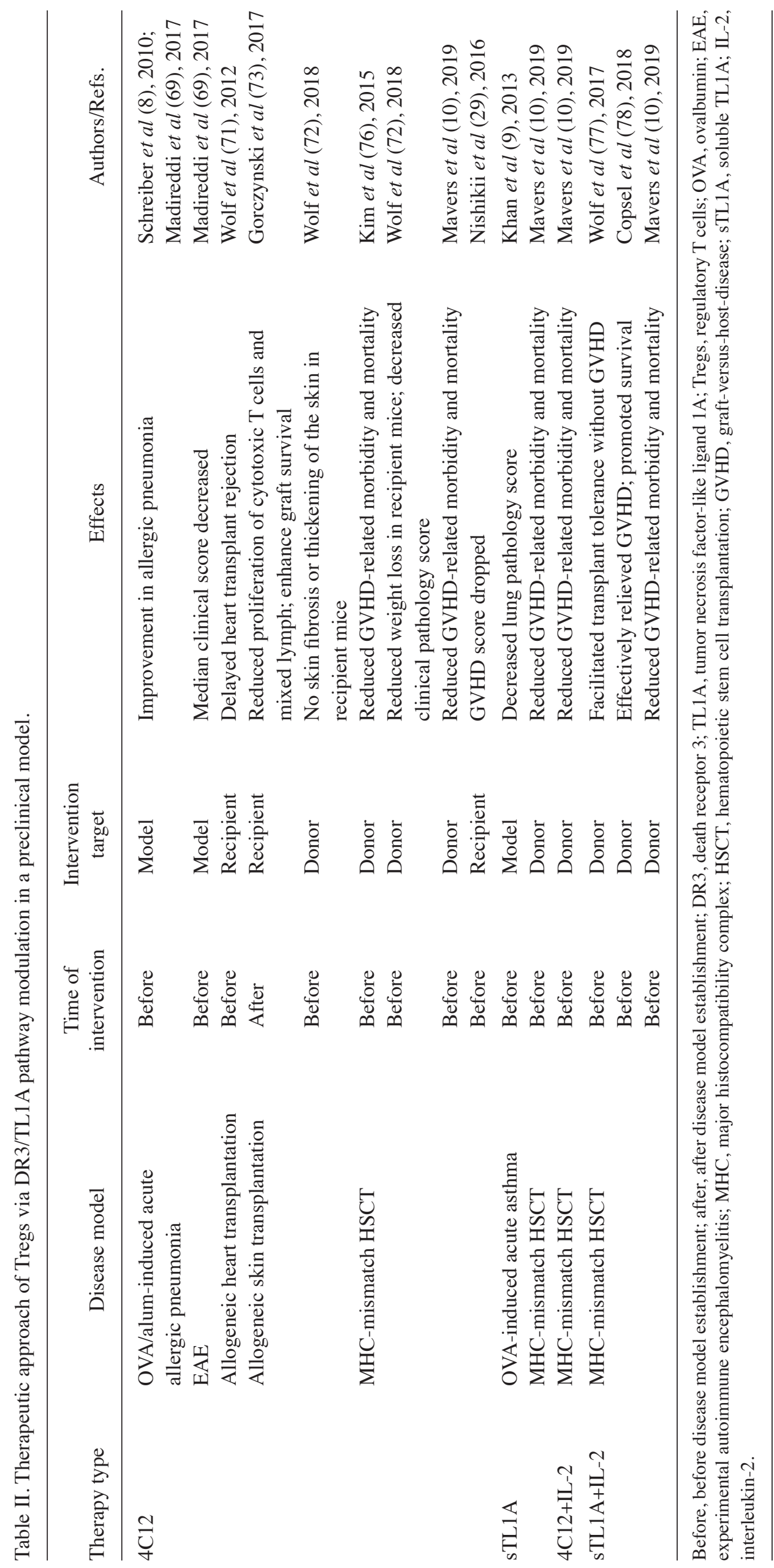


sTL1A. In addition to the anti-DR3 agonistic antibody, which may induce rapid and selective expansion of Tregs, sTL1A is sufficient as a soluble ligand for DR3 to trigger its signaling and to expand Tregs in vivo (9). Due to the shorter half-life of sTL1A $(13.5 \mathrm{~h})$, daily injection is required to maintain the desired serum levels. Khan et al (9) reported that sTL1A-meditated Treg expansion alleviated allergic lung inflammation through repeated administration, by blocking eosinophil infiltration into the alveolar fluid and reversing the ratio of Tconvs to Tregs in the lung without inducing any inflammatory changes in the liver, kidney and myocardium. Additionally, sTL1A, alone or combined with IL-2-expanded and IL-2-activated Tregs in donor mice, led to decreased GVHD morbidity and mortality in HSCT models (10). Consistent with this observation, low-dose IL-2 combined with sTL1A improved the clinical score, dampened weight loss and increased survival prior to HSCT exposure in animal models $(77,78)$. Low-dose IL-2 combined with sTL1A expanded a higher proportion of Tregs in the peripheral blood, lymph nodes and spleen, compared with sTL1A alone (10). Whether the activation of Tregs through sTL1A/IL-2 may prevent GVHD manifestations more effectively than the treatment regimen of sTL1A requires further investigation.

\section{Conclusions and perspectives}

In conclusion, activation of the DR3/TL1A pathway has been reported to alleviate allergic lung inflammation, improve EAE symptoms and abrogate GVHD (Table II). Physiologically, DR3 triggers pro-inflammatory and anti-inflammatory effects. Blockade of DR3 signaling through anti-TL1A mAb exerts anti-inflammatory effects by suppressing effector immune cell activation. As anti-TL1A mAb is a neutralizing antibody, the receptor-binding epitope and binding avidity may affect antibody activity. As DR3 and Decoy receptor 3 (DcR3) are receptors for TL1A, whether an antibody preferentially inhibits TL1A binding to DR3 or to DcR3 should be determined during antibody discovery campaigns. Additionally, activation of the DR3/TL1A axis via 4C12, sTL1A or in combination with IL-2 shows distinct immunosuppressive functions and controls aberrant immune reactions. Due to the dose-dependent, DR3-mediated expansion of Tregs, it is necessary to determine the optimal dose for Treg-based therapies. During the development of an anti-DR3 agonistic antibody, attention should be paid to Fc $\gamma$ R-induced cellular cytotoxicity so as to realize the full agonistic potential, while limiting binding to $\mathrm{Fc} \gamma \mathrm{R}$. Therapeutically, interfering with the DR3/TL1A pathway in preclinical models has shown great promise. Neutralizing antibodies and agonists activating the DR3/TL1A pathway are required to target inflammatory and immune-mediated diseases.

\section{Acknowledgements}

Not applicable.

\section{Funding}

The present study was funded by the National Natural Science Foundation of China (grant no. 31801192) and
CAMS Innovation Fund for Medical Sciences (grant no. 2016-12M-3-024).

\section{Availability of data and materials}

Not applicable.

\section{Authors' contributions}

YY and PJ designed the review. PS and NS analyzed the relevant literature. YY drafted the manuscript and constructed the figure. PJ edited the manuscript and constructed the tables. FL provided financial resources and edited the manuscript. All authors read and approved the final manuscript.

\section{Ethics approval and consent to participate}

Not applicable.

\section{Patient consent for publication}

Not applicable.

\section{Competing interests}

The authors declare that they have no competing interests.

\section{References}

1. Dostert C, Grusdat M, Letellier E and Brenner D: The TNF Family of Ligands and Receptors: Communication Modules in the Immune System and Beyond. Physiol Rev 99: 115-160, 2019.

2. Aggarwal BB, Gupta SC and Kim JH: Historical perspectives on tumor necrosis factor and its superfamily: 25 years later, a golden journey. Blood 119: 651-665, 2012

3. Yang Y, Yeh SH, Madireddi S, Matochko WL, Gu C, Pacheco Sanchez P, Ultsch M, De Leon Boenig G, Harris SF, Leonard B, et al: Tetravalent biepitopic targeting enables intrinsic antibody agonism of tumor necrosis factor receptor superfamily members. MAbs 11: 996-1011, 2019.

4. Valatas V, Kolios G and Bamias G: TL1A (TNFSF15) and DR3 (TNFRSF25): A Co-stimulatory System of Cytokines With Diverse Functions in Gut Mucosal Immunity. Front Immunol 10: $583,2019$.

5. Li L, Fu L, Zhou P, Lu Y, Zhang L, Wang W, Nie J, Zhang D, Liu Y, Wu B, et al: Effects of tumor necrosis factor-like ligand 1A (TL1A) on imiquimod-induced psoriasiform skin inflammation in mice. Arch Dermatol Res 312: 481-490, 2020.

6. Clarke AW, Poulton L, Shim D, Mabon D, Butt D, Pollard M, Pande V, Husten J, Lyons J, Tian C, et al: An anti-TL1A antibody for the treatment of asthma and inflammatory bowel disease. MAbs 10: 664-677, 2018.

7. Richard AC, Tan C, Hawley ET, Gomez-Rodriguez J, Goswami R, Yang XP, Cruz AC, Penumetcha P, Hayes ET, Pelletier M, et al: The TNF-family ligand TL1A and its receptor DR3 promote $\mathrm{T}$ cell-mediated allergic immunopathology by enhancing differentiation and pathogenicity of IL-9-producing T cells. J Immunol 194: 3567-3582, 2015

8. Schreiber TH, Wolf D, Tsai MS, Chirinos J, Deyev VV, Gonzalez L, Malek TR, Levy RB and Podack ER: Therapeutic Treg expansion in mice by TNFRSF 25 prevents allergic lung inflammation. J Clin Invest 120: 3629-3640, 2010.

9. Khan SQ, Tsai MS, Schreiber TH, Wolf D, Deyev VV and Podack ER: Cloning, expression, and functional characterization of TL1A-Ig. J Immunol 190: 1540-1550, 2013.

10. Mavers M, Simonetta F, Nishikii H, Ribado JV, Maas-Bauer K, Alvarez M, Hirai T, Turkoz M, Baker J and Negrin RS: Activation of the DR3-TL1A Axis in Donor Mice Leads to Regulatory T Cell Expansion and Activation With Reduction in Graft-Versus-Host Disease. Front Immunol 10: 1624, 2019. 
11. Chinnaiyan AM, O'Rourke K, Yu GL, Lyons RH, Garg M, Duan DR, Xing L, Gentz R, Ni J and Dixit VM: Signal transduction by DR3, a death domain-containing receptor related to TNFR-1 and CD95. Science 274: 990-992, 1996.

12. Perks WV, Singh RK, Jones GW, Twohig JP, Williams AS, Humphreys IR, Taylor PR, Jones SA and Wang ECY: Death Receptor 3 Promotes Chemokine-Directed Leukocyte Recruitment in Acute Resolving Inflammation and Is Essential for Pathological Development of Mesothelial Fibrosis in Chronic Disease. Am J Pathol 186: 2813-2823, 2016.

13. Wang EC, Kitson J, Thern A, Williamson J, Farrow SN and Owen MJ: Genomic structure, expression, and chromosome mapping of the mouse homologue for the WSL-1 (DR3, Apo3, TRAMP, LARD, TR3, TNFRSF12) gene. Immunogenetics 53: $59-63,2001$.

14. Screaton GR, Xu XN, Olsen AL, Cowper AE, Tan R, McMichael AJ and Bell JI: LARD: A new lymphoid-specific death domain containing receptor regulated by alternative pre-mRNA splicing. Proc Natl Acad Sci USA 94: 4615-4619, 1997.

15. Schreiber TH and Podack ER: Immunobiology of TNFSF15 and TNFRSF25. Immunol Res 57: 3-11, 2013.

16. Gout S, Morin C, Houle F and Huot J: Death receptor-3, a new E-Selectin counter-receptor that confers migration and survival advantages to colon carcinoma cells by triggering p38 and ERK MAPK activation. Cancer Res 66: 9117-9124, 2006.

17. Al-Lamki RS, Wang J, Thiru S, Pritchard NR, Bradley JA, Pober JS and Bradley JR: Expression of silencer of death domains and death-receptor-3 in normal human kidney and in rejecting renal transplants. Am J Pathol 163: 401-411, 2003.

18. Liu W, Vetreno RP and Crews FT: Hippocampal TNF-death receptors, caspase cell death cascades, and IL-8 in alcohol use disorder. Mol Psychiatry: Mar 5, 2020 (Epub ahead of print) doi: 10.1038/s41380-020-0698-4.

19. Bittner S and Ehrenschwender M: Multifaceted death receptor 3 signaling-promoting survival and triggering death. FEBS Lett 591: 2543-2555, 2017.

20. Collins FL, Stone MD, Turton J, McCabe LR, Wang ECY and Williams AS: Oestrogen-deficiency induces bone loss by modulating $\mathrm{CD}_{14}{ }^{+}$monocyte and $\mathrm{CD} 4^{+} \mathrm{T}$ cell DR3 expression and serum TL1A levels. BMC Musculoskelet Disord 20: 326 , 2019.

21. Della Bella S, Calcaterra F, Bacci M, Carenza C, Pandolfo C, Ferrazzi P, Uva P, Pagani M, Lodigiani C and Mavilio D Pathologic up-regulation of TNFSF15-TNFRSF25 axis sustains endothelial dysfunction in unprovoked venous thromboembolism. Cardiovasc Res 116: 698-707, 2020.

22. Slebioda TJ, Bojarska-Junak A, Cyman M, Landowski P Kaminska B, Celinski K and Kmiec Z: Expression of death receptor 3 on peripheral blood mononuclear cells differes in adult IBD patients and children with newly diagnosed IBD Cytometry B Clin Cytom 92: 165-169, 2017.

23. Facco M, Cabrelle A, Calabrese F, Teramo A, Cinetto F, Carraro S Martini V, Calzetti F, Tamassia N, Cassatella MA, et al: TL1A/DR3 axis involvement in the inflammatory cytokine network during pulmonary sarcoidosis. Clin Mol Allergy 13: 16 , 2015.

24. Li L, Lu Y, Fu L, Zhou P, Zhang L, Wang W, Nie J, Zhang D, Liu Y, Wu B, et al: Expression of death receptor 3 (DR3) on peripheral blood mononuclear cells of patients with psoriasis vulgaris. Postgrad Med J 94: 551-555, 2018.

25. Safaya S, Alfarhan M, Sulaiman A, Alsulaiman A and Al-Ali A TNFSF/TNFRSF cytokine gene expression in sickle cell anemia: Up-regulated TNF-like cytokine 1A (TL1A) and its decoy receptor (DcR3) in peripheral blood mononuclear cells and plasma. Cytokine 123: 154744, 2019.

26. Slebioda TJ, Stanisławowski M, Cyman M, Wierzbicki PM, Żurawa-Janicka D, Kobiela J, Makarewicz W, Guzek M and Kmieć Z: Distinct Expression Patterns of Two Tumor Necrosis Factor Superfamily Member 15 Gene Isoforms in Human Colon Cancer. Dig Dis Sci 64: 1857-1867, 2019.

27. Bittner S, Knoll G, Füllsack S, Kurz M, Wajant H and Ehrenschwender M: Soluble TL1A is sufficient for activation of death receptor 3. FEBS J 283: 323-336, 2016

28. Li Z, Buttó LF, Buela KA, Jia LG, Lam M, Ward JD, Pizarro TT and Cominelli F: Death Receptor 3 Signaling Controls the Balance between Regulatory and Effector Lymphocytes in SAMP1/YitFc Mice with Crohn's Disease-Like Ileitis. Front Immunol 9: 362, 2018.
29. Nishikii H, Kim BS, Yokoyama Y, Chen Y, Baker J, Pierini A, Alvarez M, Mavers M, Maas-Bauer K, Pan Y, et al: DR3 signaling modulates the function of $\mathrm{Foxp}^{+}$regulatory $\mathrm{T}$ cells and the severity of acute graft-versus-host disease. Blood 128 2846-2858, 2016

30. Xu LX, Grimaldo S, Qi JW, Yang GL, Qin TT, Xiao HY, Xiang R, Xiao Z, Li LY and Zhang ZS: Death receptor 3 mediates TNFSF15- and TNF $\alpha$-induced endothelial cell apoptosis. Int J Biochem Cell Biol 55: 109-118, 2014.

31. ButtóLF,JiaLG,ArseneauKO,TamagawaH,Rodriguez-Palacios A, Li Z, De Salvo C, Pizarro TT, Bamias G and Cominelli F: Death-Domain-Receptor 3 Deletion Normalizes Inflammatory Gene Expression and Prevents Ileitis in Experimental Crohn's Disease. Inflamm Bowel Dis 25: 14-26, 2019.

32. Li J, Shi W, Sun H, Ji Y, Chen Y, Guo X, Sheng H, Shu J, Zhou L, Cai T, et al: Activation of DR3 signaling causes loss of ILC3s and exacerbates intestinal inflammation. Nat Commun 10: 3371, 2019.

33. Castellanos JG, Woo V, Viladomiu M,Putzel G,Lima S, Diehl GE, Marderstein AR, Gandara J, Perez AR, Withers DR, et al: Microbiota-Induced TNF-like Ligand 1A Drives Group 3 Innate Lymphoid Cell-Mediated Barrier Protection and Intestinal T Cell Activation during Colitis. Immunity 49: 1077-1089.e5, 2018.

34. Karta MR, Broide DH and Doherty TA: Insights into Group 2 Innate Lymphoid Cells in Human Airway Disease. Curr Allergy Asthma Rep 16: 8, 2016

35. Singh RK, Perks WV, Twohig JP, Kidd EJ, Broadley K, Farrow SN Williams AS, Taylor PR and Wang ECY: Death Receptor 3 regulates distinct pathological attributes of acute versus chronic murine allergic lung inflammation. Cell Immunol 320: 62-70, 2017.

36. Jin S, Chin J, Seeber S, Niewoehner J, Weiser B, Beaucamp N, Woods J, Murphy C, Fanning A, Shanahan F, et al: TL1A/TNFSF15 directly induces proinflammatory cytokines, including $\mathrm{TNF} \alpha$, from $\mathrm{CD}^{+} \mathrm{CD} 161^{+} \mathrm{T}$ cells to exacerbate gut inflammation. Mucosal Immunol 6: 886-899, 2013.

37. Papadakis KA, Zhu D, Prehn JL, Landers C, Avanesyan A, Lafkas $G$ and Targan SR: Dominant role for TL1A/DR3 pathway in IL-12 plus IL-18-induced IFN-gamma production by peripheral blood and mucosal CCR9 ${ }^{+} \mathrm{T}$ lymphocytes. J Immunol 174: 4985-4990, 2005.

38. Siakavellas SI and Bamias G: Tumor Necrosis Factor-like Cytokine TL1A and Its Receptors DR3 and DcR3: Important New Factors in Mucosal Homeostasis and Inflammation. Inflamm Bowel Dis 21: 2441-2452, 2015.

39. Fang L, Adkins B, Deyev V and Podack ER: Essential role of TNF receptor superfamily 25 (TNFRSF25) in the development of allergic lung inflammation. J Exp Med 205: 1037-1048, 2008.

40. Meylan F,Davidson TS,KahleE,KinderM,Acharya K,Jankovic D, Bundoc V, Hodges M, Shevach EM, Keane-Myers A, et al: The TNF-family receptor DR3 is essential for diverse T cell-mediated inflammatory diseases. Immunity 29: 79-89, 2008.

41. Basnyat P, Sumelahti ML, Lehtimäki T, Elovaara I and Hagman S: Gene expression profiles of TNF-like cytokine 1A (TL1A) and its receptors death receptor 3 (DR3) and decoy receptor 3 (DcR3) in multiple sclerosis. J Neuroimmunol 335: 577020,2019

42. Jones GW, Stumhofer JS, Foster T, Twohig JP, Hertzog P, Topley N, Williams AS, Hunter CA, Jenkins BJ, Wang EC, et al: Naive and activated $T$ cells display differential responsiveness to TL1A that affects Th17 generation, maintenance, and proliferation. FASEB J 25: 409-419, 2011.

43. Zhou M, Liu R, Su D, Feng X and Li X: TL1A increased the differentiation of peripheral Th17 in rheumatoid arthritis. Cytokine 69: 125-130, 2014

44. Pappu BP, Borodovsky A, Zheng TS, Yang X, Wu P, Dong X Weng S, Browning B, Scott ML, Ma L, et al: TL1A-DR3 interaction regulates Th17 cell function and Th17-mediated autoimmune disease. J Exp Med 205: 1049-1062, 2008.

45. Wang D, Li H, Duan YY, Han F, Luo YX, Wu MY, Yang MY, Zhan RR, Song J, Zhang H, et al: TL1A modulates the severity of colitis by promoting Th9 differentiation and IL-9 secretion. Life Sci 231: 116536, 2019.

46. Tsuda M, Hamade H, Thomas LS, Salumbides BC, Potdar AA, Wong MH, Nunnelee JS, Stamps JT, Neutzsky-Wulff AV, Barrett RJ, et al: A role for BATF3 in TH9 differentiation and T-cell-driven mucosal pathologies. Mucosal Immunol 12: 644-655, 2019 
47. MeylanF,HawleyET,BarronL,BarlowJL,PenumetchaP,PelletierM, Sciumè G, Richard AC, Hayes ET, Gomez-Rodriguez J, et al: The TNF-family cytokine TL1A promotes allergic immunopathology through group 2 innate lymphoid cells. Mucosal Immunol 7 : 958-968, 2014.

48. Castellanos JG and Longman RS: Innate lymphoid cells link gut microbes with mucosal T cell immunity. Gut Microbes 11: 231-236, 2020.

49. Bull MJ, Williams AS, Mecklenburgh Z, Calder CJ, Twohig JP, Elford C, Evans BA, Rowley TF, Slebioda TJ, Taraban VY, et al: The Death Receptor 3-TNF-like protein 1A pathway drives adverse bone pathology in inflammatory arthritis. J Exp Med 205: 2457-2464, 2008.

50. Tougaard P, Zervides KA, Skov S, Hansen AK and Pedersen AE: Biologics beyond TNF- $\alpha$ inhibitors and the effect of targeting the homologues TL1A-DR3 pathway in chronic inflammatory disorders. Immunopharmacol Immunotoxicol 38: 29-38, 2016.

51. Takedatsu H, Michelsen KS, Wei B, Landers CJ, Thomas LS, Dhall D, Braun J and Targan SR: TL1A (TNFSF15) regulates the development of chronic colitis by modulating both T-helper 1 and T-helper 17 activation. Gastroenterology 135: 552-567, 2008

52. Meylan F, Song YJ, Fuss I, Villarreal S, Kahle E, Malm IJ, Acharya K, Ramos HL, Lo L, Mentink-Kane MM, et al: The TNF-family cytokine TL1A drives IL-13-dependent small intestinal inflammation. Mucosal Immunol 4: 172-185, 2011.

53. Shih DQ, Zheng L, Zhang X, Zhang H, Kanazawa Y, Ichikawa R, Wallace KL, Chen J, Pothoulakis C, Koon HW, et al: Inhibition of a novel fibrogenic factor Tl1a reverses established colonic fibrosis. Mucosal Immunol 7: 1492-1503, 2014

54. Li H, Song J, Niu G, Zhang H, Guo J, Shih DQ, Targan SR and Zhang X: TL1A blocking ameliorates intestinal fibrosis in the T cell transfer model of chronic colitis in mice. Pathol Res Pract 214: 217-227, 2018.

55. Deng G, Song X and Greene MI: FoxP3 in Treg cell biology: A molecular and structural perspective. Clin Exp Immunol 199: 255-262, 2020

56. Williams LM and Rudensky AY: Maintenance of the Foxp3-dependent developmental program in mature regulatory $\mathrm{T}$ cells requires continued expression of Foxp3. Nat Immunol 8 277-284, 2007.

57. Allos H, Al Dulaijan BS, Choi J and Azzi J: Regulatory T Cells for More Targeted Immunosuppressive Therapies. Clin Lab Med 39: 1-13, 2019.

58. Lubrano di Ricco M, Ronin E, Collares D, Divoux J, Grégoire S, Wajant H, Gomes T, Grinberg-Bleyer Y, Baud V, Marodon G, et al: Tumor necrosis factor receptor family costimulation increases regulatory T-cell activation and function via NF- $\kappa \mathrm{B}$. Eur J Immunol 50: 972-985, 2020.

59. Bittner S, Knoll G and Ehrenschwender M: Death receptor 3 signaling enhances proliferation of human regulatory $\mathrm{T}$ cells FEBS Lett 591: 1187-1195, 2017.

60. Tran GT, Hodgkinson SJ, Carter N, Verma ND, Robinson CM, Plain KM, Nomura M and Hall BM: Autoantigen specific IL-2 activated $\mathrm{CD} 4{ }^{+} \mathrm{CD} 25^{+} \mathrm{T}$ regulatory cells inhibit induction of experimental autoimmune neuritis. J Neuroimmunol 341: 577186, 2020.

61. Zhang J, Czerpaniak K, Huang L, Liu X, Cloud ME, Unsinger J, Hotchkiss RS, Li D and Cao YQ: Low-dose interleukin-2 reverses behavioral sensitization in multiple mouse models of headache disorders. Pain 161: 1381-1398, 2020.

62. Scalapino KJ, Tang Q, Bluestone JA, Bonyhadi ML and Daikh DI: Suppression of disease in New Zealand Black/New Zealand White lupus-prone mice by adoptive transfer of ex vivo expanded regulatory T cells. J Immunol 177: 1451-1459, 2006.

63. Canavan JB, Scottà C, Vossenkämper A, Goldberg R, Elder MJ, Shoval I, Marks E, Stolarczyk E, Lo JW, Powell N, et al: Developing in vitro expanded CD45RA ${ }^{+}$regulatory T cells as an adoptive cell therapy for Crohn's disease. Gut 65: 584-594, 2016.

64. Golshayan D, Jiang S, Tsang J, Garin MI, Mottet C and Lechler RI In vitro-expanded donor alloantigen-specific $\mathrm{CD} 4{ }^{+} \mathrm{CD} 25^{+}$regulatory $\mathrm{T}$ cells promote experimental transplantation tolerance. Blood 109: 827-835, 2007.
65. Xia G, He J and Leventhal JR: Ex vivo-expanded natural $\mathrm{CD} 4{ }^{+} \mathrm{CD} 25^{+}$regulatory $\mathrm{T}$ cells synergize with host $\mathrm{T}$-cell depletion to promote long-term survival of allografts. Am J Transplant 8: 298-306, 2008.

66. Matsuoka KI: Low-dose interleukin-2 as a modulator of Treg homeostasis after HSCT: Current understanding and future perspectives. Int J Hematol 107: 130-137, 2018

67. Kapur R, Kim M, Aslam R, McVey MJ, Tabuchi A, Luo A, Liu J, Li Y, Shanmugabhavananthan S, Speck ER, et al: T regulatory cells and dendritic cells protect against transfusion-related acute lung injury via IL-10. Blood 129: 2557-2569, 2017.

68. He R, Li L, Kong Y, Tian L, Tian X, Fang P, Bian M and Liu Z: Preventing murine transfusion-related acute lung injury by expansion of $\mathrm{CD}^{+}{ }^{+} \mathrm{CD} 25^{+}$FoxP $3^{+}$Tregs using IL-2/anti-IL-2 complexes. Transfusion 59: 534-544, 2019.

69. Madireddi S, Eun SY, Mehta AK, Birta A, Zajonc DM, Niki T, Hirashima M, Podack ER, Schreiber TH and Croft M: Regulatory T Cell-Mediated Suppression of Inflammation Induced by DR3 Signaling Is Dependent on Galectin-9. J Immunol 199: 2721-2728, 2017.

70. Schreiber TH, Wolf D, Bodero M, Gonzalez L and Podack ER T cell costimulation by TNFR superfamily (TNFRSF) 4 and TNFRSF25 in the context of vaccination. J Immunol 189 3311-3318, 2012

71. Wolf D, Schreiber TH, Tryphonopoulos P, Li S, Tzakis AG, Ruiz P and Podack ER: Tregs expanded in vivo by TNFRSF25 agonists promote cardiac allograft survival. Transplantation 94 : 569-574, 2012

72. Wolf D, Bader CS, Barreras H, Copsel S, Pfeiffer BJ, Lightbourn CO, Altman NH, Komanduri KV and Levy RB: Superior immune reconstitution using Treg-expanded donor cells versus PTCy treatment in preclinical HSCT models. JCI Insight 3: e121717, 2018.

73. Gorczynski RM, Sadozai H,Zhu F and Khatri I: Effect of infusion of monoclonal antibodies to tumour necrosis factor-receptor super family 25 on graft rejection in allo-immune mice receiving autologous marrow transplantation. Immunology 150: 418-431, 2017.

74. Pierini A, Colonna L, Alvarez M, Schneidawind D, Nishikii H, Baker J, Pan Y, Florek M, Kim BS and Negrin RS: Donor Requirements for Regulatory T Cell Suppression of Murine Graft-versus-Host Disease. J Immunol 195: 347-355, 2015.

75. Hoffmann P, Ermann J, Edinger M, Fathman CG and Strober S: Donor-type CD4(+)CD25(+) regulatory T cells suppress lethal acute graft-versus-host disease after allogeneic bone marrow transplantation. J Exp Med 196: 389-399, 2002.

76. Kim BS, Nishikii H, Baker J, Pierini A, Schneidawind D, Pan Y, Beilhack A, Park CG and Negrin RS: Treatment with agonistic DR3 antibody results in expansion of donor Tregs and reduced graft-versus-host disease. Blood 126: 546-557, 2015.

77. Wolf D, Barreras H, Bader CS, Copsel S, Lightbourn CO, Pfeiffer BJ, Altman NH, Podack ER, Komanduri KV and Levy RB: Marked In Vivo Donor Regulatory T Cell Expansion via Interleukin-2 and TL1A-Ig Stimulation Ameliorates Graft-versus-Host Disease but Preserves Graft-versus-Leukemia in Recipients after Hematopoietic Stem Cell Transplantation. Biol Blood Marrow Transplant 23: 757-766, 2017.

78. Copsel S, Wolf D, Kale B, Barreras H, Lightbourn CO, Bader CS, Alperstein W, Altman NH, Komanduri KV and Levy RB: Very Low Numbers of CD4 ${ }^{+}$FoxP3 ${ }^{+}$Tregs Expanded in Donors via TL1A-Ig and Low-Dose IL-2 Exhibit a Distinct Activation/Functional Profile and Suppress GVHD in a Preclinical Model. Biol Blood Marrow Transplant 24: 1788-1794, 2018.

This work is licensed under a Creative Commons Attribution-NonCommercial-NoDerivatives 4.0 International (CC BY-NC-ND 4.0) License. 